\title{
Influence of parasitoid Paravilla sp. (Diptera, Bombyliidae) on the development of larvae of Myrmeleon brasiliensis (Návas, 1914) (Neuroptera, Myrmeleontidae)
}

\author{
Lucimara Modesto Nonato ${ }^{1}$; Gustavo Graciolli² \& Tatiane do Nascimento Lima ${ }^{3}$ \\ 1 Universidade Federal de Mato Grosso do Sul (UFMS), Instituto de Biociências (INBI0), Programa de Pós-Graduação em Ecologia e Conservação \\ (PPGEC). Campo Grande, MS, Brasil. E-mail: lunonato@gmail.com \\ ${ }^{2}$ Universidade Federal de Mato Grosso do Sul (UFMS), Instituto de Biociências (INBI0), Laboratório de Sistemática, Ecologia e Evolução (LSEE). \\ Campo Grande, MS, Brasil. ORCID: 0000-0002-1144-3486. E-mail: ggraciolli@yahoo.com.br \\ ${ }^{3}$ Universidade Federal de Mato Grosso do Sul (UFMS), Instituto de Biociências (INBIO), Laboratório de Síntese em Biodiversidade (LSB). \\ Aquidauana, MS, Brasil. ORCID: 0000-0002-0656-1170. E-mail: tatianenlima@gmail.com (corresponding author)
}

\begin{abstract}
Parasitoids manipulate the host metabolism for their own benefit by influencing its development and the direct or indirect result of it is the host death. This study aimed to observe the influence of parasitoidism of Paravilla sp. (Diptera, Bombyliidae) on the development of antlion larvae Myrmeleon brasiliensis (Návas, 1914) (Neuroptera, Myrmeleontidae). The specific objectives were to verify in which larval instars the parasitoid oviposition occurs, the influence of the parasitoid on the larval and pupal development time of $M$. brasiliensis, the differences in body length of the antlion larvae, as well as of the sex ratio of $M$. brasiliensis adults. For this, the larvae were differentiated in $1^{\text {st }}, 2^{\text {nd }}$ and $3^{\text {rd }}$ instar and measures on body length (head-abdomen) and accompanied until the emergence of the adult. It was observed that the parasitoid Paravilla sp. attacked only the $2^{\text {nd }}$ and $3^{\text {rd }}$ instar larvae. The parasitoid Paravilla sp. oviposited only in $2^{\text {nd }}$ and $3^{\text {rd }}$ instars larvae. No significant differences were observed on larval development time, in the larval body length and in the adult sex ratio between groups of parasitized and non-parasitized $M$. brasiliensis larvae, however, was observed differences in the pupal development time of these two groups. Thus, we can conclude that the parasitoid Paravilla sp. influences the development time of M. brasiliensis pupal.
\end{abstract}

Key-Words. Antlion; Bombyliidae; Immature stages; Parasitoid.

\section{INTRODUCTION}

Parasitoids are insects that develop on or in a single organism, obtaining nutrients from the host and generally leading to its death (Eggleton \& Gaston, 1990). The recognition of the quality of the host on the part of parasitoid females indicates that the host has adequate nutritional and physiological characteristics for the development of larval forms of the parasitoid (Mackauer et al., 1996). The relationship between the host characteristics at the time of parasitoidism and the gain in performance of the parasitoid is not linear and depends on a combination of factors host-related, such as physiology and behavior (Colinet et al., 2005). It is not yet clear how parasitoids manipulate the host metabolism for their own benefit, however has been suggested that parasitoids may perturb the absorption of nutrients of the hemolymph so that more nutrients are available to them (Fisher, 1971; Slansky, 1986; Sequeira \& Mackauer, 1992; Vinson \& Iwantsch, 1980). Parasitoids use a variety of methods to create an environment that is favorable to their survival, such as diminishing the activity of the host immune system, thereby affecting the action of hormones and defense behavior (Beckage \& Gelman, 2004).

Larvae of antlions of genus Myrmeleon Linnaeus, 1767 (Neuroptera, Myrmeleontidae) are "sit-and-wait" predators that build traps in the form of a pit dug into sandy soil to capture prey. These insects inhabit warm regions and are spatially restricted to open areas with sandy substrate that are reasonably protected from rain (Farji-Brener, 2003; Lima \& Faria, 2007). Larvae of the antlion species Myrmeleon brasiliensis (Návas, 1914) build traps ranging from 9.19 to $35.21 \mathrm{~mm}$ in diameter (Nonato \& Lima, 2011) and pass through three instars (each lasting an average of 26 days) prior to the formation of the pupae (Missirian et al., 2006). The size of the pit is positively related to body size; the transition from one instar to the next leads to a larger size of the larva and, consequently, larger trap size. In the first, second and third instars, $M$. brasiliensis larvae build traps with a mean ( \pm standard deviation) diameter 
of $14.7 \pm 5.51,19.8 \pm 4.96$ and $27.0 \pm 7.31 \mathrm{~mm}$, respectively. These larvae are commonly found in Savana areas in the state of Mato Grosso do Sul (Nonato \& Lima, 2011).

In the family Myrmeleontidae, cases of parasitoidism by dipterans of the family Bombyliidae (Baba et al., 1987) and hymenopterans of the family Chalcididae (Steffan, 1961; Wheeler, 1930) have been recorded. Uchôa \& Missirian (2014) recently reported larvae of the antlion M. brasiliensis in the state of Mato Grosso do Sul, Brazil, parasitized by Hockeria sp. (Wallace, 1942) (Hymenoptera, Chalcididae) and Paravilla sp. (Wiedemann, 1828) (Diptera, Bombylliidae), but the authors did not evaluate the influence of the parasitoids on the development of the larvae.

The aim of the present study was to determine the influence of parasitoidism of Paravilla sp. on the development of larvae of the antlion M. brasiliensis. For such, the following aspects were evaluated to parasitized and non-parasitized larvae: in which antlion larval instars the parasitoid oviposition occurs; development time of larvae and pupae; body length (head-abdomen) of M. brasiliensis larvae parasitized and non-parasitized; the sex ratio of male and female adults emerged from no parasitized larvae.

\section{MATERIAL AND METHODS}

Myrmeleon brasiliensis (Návas, 1914) larvae were collected from the municipality of Aquidauana in a permanent protection area pertaining to the State University of Mato Grosso do Sul in central western Brazil $\left(20^{\circ} 26^{\prime} 25^{\prime \prime} S\right.$, $\left.55^{\circ} 39^{\prime} 21^{\prime \prime} \mathrm{W}\right)$. The experiments were conducted at the Zoology Laboratory of the Federal University of Mato Grosso do Sul (December 2011 to July 2012).

Collected larvae of $M$. brasiliensis were taken to the laboratory in plastic bags containing sand from the origin location. To differentiate instars, body length (head-abdomen) and head capsule width of the specimens were measured using digital calipers (precision: $0.01 \mathrm{~mm}$ ). After sorting, the specimens were placed individually into transparent plastic recipients $(13 \mathrm{~cm}$ in height and $10 \mathrm{~cm}$ in diameter) containing sand. In the laboratory the larvae of $M$. brasiliensis were kept under conditions of temperature and ambient humidity, without manipulation.

Two hundred forty-one larvae were monitored (40 of $1^{\text {st }}$ instar, 71 of $2^{\text {nd }}$ instar and 130 of $3^{\text {rd }}$ instar) until the emergence of the adults. To ensure development, each specimen was offered a larva of Drosophila melanogaster Meigen, 1830 from the insect rearing laboratory of the university each day as food.

The period in which $3^{\text {rd }}$ instar larvae were active with trap building was denominated "pit time" and the period that trap building ceased (pupal phase) was denominated "pupal time". When $3^{\text {rd }}$ instar specimens entered the pupal phase, the plastic recipients were covered with cloth screen to impede the emerged adults (parasitoids or $M$. brasiliensis) from escaping. After the emergence of the adults, the larval instar of the specimens at the beginning of the experiment was confirmed by the number of molts that occurred for each larva (observed during daily monitoring of development in the individual recipients).

Pit time (time in which $3^{\text {rd }}$ instar larvae remained in predation activity) and total $3^{\text {rd }}$ instar development time (pit time + pupal time) were compared using the Wilcoxon rank sum test only for larvae collected in the $2^{\text {nd }}$ instar phase in the field (specimens monitored in the laboratory until the transition to the $3^{\text {rd }}$ instar phase), since it was not possible to determine whether $3^{\text {rd }}$ instar larvae collected in the field were in the beginning, middle or end of the active period. The time in which the larvae remained inactive in the pit after having reached the $3^{\text {rd }}$ instar (pupal time until emergence of the adult) was compared using the Wilcoxon rank sum test for all three instars, since all specimens were in the laboratory when this occurred and the exact time of this period could therefore be determined. Body size of parasitized and non-parasitized larvae was compared using the Wilcoxon rank sum test. Sexing of the emergent $M$. brasiliensis adults was performed based on Jurberg (1963) and the sex ratio was determined using the chi-square test. All statistical analyses were conducted using the R software environment (R Core Team, 2013).

\section{RESULTS}

During five sampling campaigns, 596 larvae were collected. 40 of first instar, 71 of second instar and 130 of third instar larvae survived through to the emergence of the adults, corresponding to a $59.56 \%$ mortality rate (241/596).

The emergence of 20 female parasitoids (Paravilla sp.) was observed (nine from larvae captured in the second instar and 11 from larvae captured in the third instar). No parasitoids emerged from Myrmeleon brasiliensis (Návas, 1914) pupae that had been captured in the first instar. The frequency of parasitoidism was $8.30 \%$ in the overall sample (20/241), $12.68 \%$ among second instar larvae (9/71) and $8.46 \%$ among third instar larvae (11/130).

Regarding the influence of parasitoidism on the behavior of the larvae, no significant difference was found between parasitized and non-parasitized larvae with regard to the time in which the specimens remained in the pit ( $\mathrm{W}=338.5 ; \mathrm{N} 1=62 ; \mathrm{N} 2=9 ; \mathrm{p}=0.059)$ or total development time in the third instar (pit time + pupal time) ( $\mathrm{W}=313.5 ; \mathrm{N} 1=62 ; \mathrm{N} 2=9 ; \mathrm{p}=0.556)$. However, a significant different was found with regard to pupal time ( $W=627 ; N 1=221 ; N 2=20 ; p=1.129$ e-07) (Fig. 1). No significant differences in body length were found between parasitized and non-parasitized larvae ( $\mathrm{W}=2238$; $\mathrm{N} 1=221 ; \mathrm{N} 2=20 ; \mathrm{p}=0.927$ ). No significant difference was found in the number of males $^{1}$ and females ${ }^{2}$ that emerged from non-parasitized larvae $\left(X^{2}\right.$ calc $=2.42$; $\left.N^{1}=89 ; N^{2}=111 ; p=0.11979\right)$.

\section{DISCUSSION}

The high mortality rate found in the present study could have been caused by different factors, such as the 
fragility of the larvae as well as the differences in temperature and humidity between the natural environment and laboratory. Matsura et al. (1998) collected 2,686 larvae of Myrmeleon bore Tjeder, 1941 in the northern region of Kyoto, Japan, among which 2,182 developed through to the emergence of the adults, which corresponds to mortality rate of $18.76 \%$. Although this rate is not as high as that in the present investigation (59.56\%), a total of 504 larvae died in the experiment, which demonstrates that mortality rate of antlion larvae is high in the laboratory setting.

The fact that no parasitoids emerged from Myrmeleon brasiliensis (Návas, 1914) pupae when the larvae were collected in the first instar lends support to models that assume that the performance of a parasitoid is related to the size of the host at the time of parasitism (Chau \& Mackauer, 2001; Nicol \& Mackauer, 1999). In the case of antlion larvae $M$. brasiliensis, body size and instar phase are related to pit size, as first instar larvae build smaller traps and are probably not potential targets of females of the parasitoid bombyliid (Nonato \& Lima, 2011). However, the number of first instar larvae was small in the present study due to the difficulty in finding larvae in this stage in the field. Thus, it is not possible to determine whether these parasitoids attack larvae in this specific instar. Matsura et al. (1998) evaluated parasitism rates by bombyliids in antlions and found that all larval instars of M. bore were parasitized by Villa myrmeleonostena Baba, 1953 (Diptera, Bombyliidae), with parasitism frequencies of $2.5 \%$ for first instar larvae, $4.3 \%$ for second instar larvae and $9.7 \%$ for third instar larvae, corresponding to an overall frequency of $6.4 \%$, which lower than the rate found in the present study (8.30\%).

Regarding the influence of parasitoidism on the time spent in the pit, although the $p$-value indicated non-significance $(p=0.059)$, the data shows that the mean time for non-parasitized and parasitized larvae was 58.5 and 38 days, respectively, indicating that the parasitoid accelerated the period which the larvae were active maintaining its pit. The same was found with regard to total development time (pit time + pupal time). Despite the p-value indicating non-significance $(p=0.556)$, the data shows that there was a small difference in median time between parasitized and non-parasitized larvae, with a generally shorter development time among the parasitized larvae.

The evidence that the parasitoid accelerated larval development may be explained by the fact that a long feeding time may increase the risk of predation or hyperparasitism, which may be aggravated when the host has several evident instars, as in the case of antlion larvae, or when normal development is affected by the physiological manipulation of the parasitoid (Beckage \& Riddiford, 1983).

With regard to the duration of the pupal phase, Paravilla sp. uses the cocoon of that the antlion larva constructs for the protection of the pupa and finalization of its metamorphosis. Thus, the duration of this phase is longer for parasitized $M$. brasiliensis larvae, since the time needed for the antlion larva to build the cocoon is added to the time the parasitoid larva takes to finish feeding on the host, pupate and finalize its development with the emergence of the adult. This behavior differs from what is frequently observed. The acceleration of the metamorphosis generally has the advantage of reducing the time needed to generate the adult and diminishes the amount of unconsumed host tissue in decomposition that poses a risk of infection to the pupa of the parasite (Godfray, 1994).

The fact that no difference in external morphology between parasitized and non-parasitized larvae, as demonstrated by the lack of a difference in body size, demonstrates that it is necessary to await the emergence of the adults to detect the presence of the parasitoids in antlion larvae, which is in agreement with data described by other authors. Observing larvae of Nophis teillardi Navás, 1912 (Neuroptera, Myrmeleontidae) parasitized by flies of the genus Thyridanthrax Osten Sacken, 1886 (Diptera, Bombyliidae), Simon (1985) found that the parasitoids (generally one per host) remained inactive throughout the development of the antlion larvae and renewed their activity only after the formation of the pupae. Baba et al. (1987) found that $19.3 \%$ of $M$. bore pupae were parasitized by larvae of $V$. myrmeleonostena and the parasitism could only be detected at the end of larval development.

Observing 10 larvae collected in Napa County, USA, Leech \& MacDonald-Leech (1989) found that seven adults of the parasitoid Dipalta serpentina Osten Sacken, 1877 (Diptera, Bombyliidae) emerged from the adults of Myrmeleon immaculatus DeGeer, 1773. Levente (1998) studied Myrmeleon inconspicuus Rambur, 1842, M. bore and Euroleon nostras (Geoffroy in Fourcroy, 1785) and found that parasitized larvae did not exhibit different behavior in comparison to non-parasitized larvae. The reason for the lack of a difference in size between larvae

Terceira Pupação

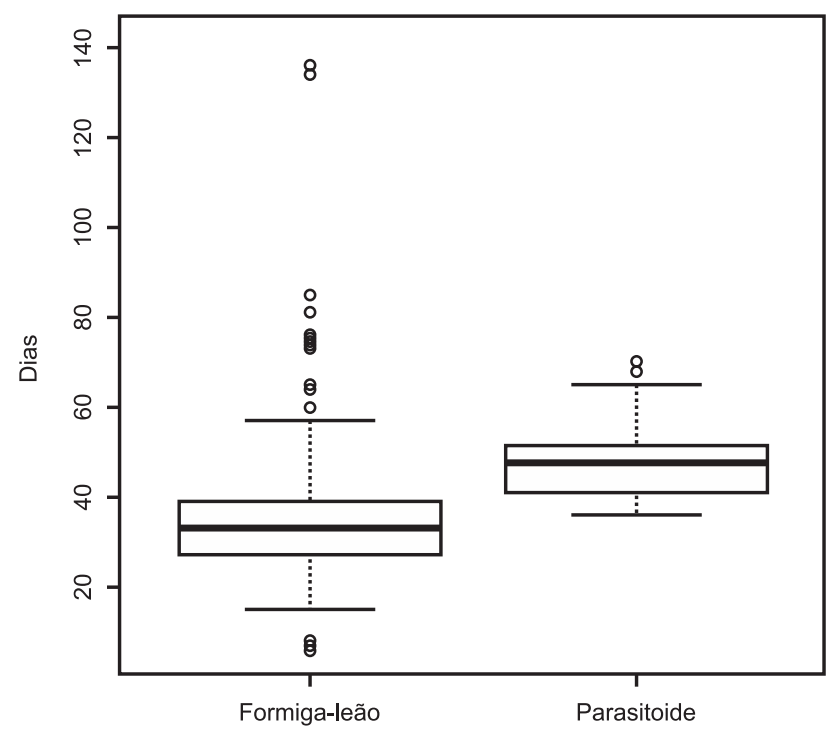

Figure 1. Number of days of pupal period until emergence of adults of Myrmeleon brasiliensis (Návas, 1914) larvae sampled in the third instar from a permanent protection area of the State University of Mato Grosso do Sul, Aquidauana, Brazil (December 2011 to July 2012). 
parasitized and non-parasitized is likely the fact that sexual dimorphism in this insect is only found in the adult phase, when females are larger than males (Arnett \& Gotelli, 1999). Regarding the sex ratio, the proportion of males to females that emerged from non-parasitized larvae was 1:1, which is similar to the ratio expected for neuropterans (New, 1991). Missirian et al. (2006) found a similar ratio for the same species.

\section{CONCLUSION}

The results of the present study demonstrated that the parasitoid Paravilla sp. only attacked Myrmeleon brasiliensis (Návas, 1914) larvae in the second and third instars and exerted an influence on development, as demonstrated by the increase in the pupal stage of the antlion. Although parasitoids exhibit a high degree of diversity, studies on parasitoids of Myrmeleon Linnaeus, 1767 in tropical regions are extremely scarce. Based on the present results, new questions regarding the development of parasitized and non-parasitized larvae can be clarified.

\section{ACKNOWLEDGMENTS}

Dr. Carlos José Einicker Lamas for the identification of the parasitoid Diptera. The funding agencies CAPES and CNPq (304616/2015-0) for granting scholarships to LNM and GG, respectively.

\section{REFERENCES}

Arnett, A.E. \& Gotell, N.J. 1999. Geographic variation in life-history traits of the antlion, Myrmeleon immaculatus: evolutionary implications of Bergmann's rule. Evolution, 53: 1180-1188.

Baba, K.; Nagatomi, A.; Nagatomi, H. \& Evenhuis, N.L. 1987. Redescription of Villa myrmeleonostena (Insecta, Diptera, Bombyliidae), a parasitoid of ant lion in Japan. Zoological Science, 4: 903-911.

Beckage, N.E. \& Gelman, B.B. 2004. Wasp parasitoid disruption of host development: implications for new biologically based strategies for insect control. Annual Review of Entomology, 49: 299-330.

Beckage, N.E. \& Riddiford, L.M. 1983. Growth and development of the endoparasitic wasp Apanteles congregatus, dependence on host nutritional status and parasitoid load. Physiological Entomology, 8: 231-241.

Chau, A. \& Mackauer, M. 2001. Host-instar selection in the aphid parasitoid Monoctonus paulensis (Hymenoptera, Braconidae, Aphidiinae): assessing costs and benefits. The Canadian Entomologist, 133: 549-564.

Colinet, H.; Salin, C.; Boivin, G. \& Hance, T.H. 2005. Host age and fitnessrelated traits in a koinobiont aphid parasitoid. Ecological Entomology, 30: 473-479.

Eggleton, P. \& Gaston, K.J. 1990. Parasitoid species and assemblages: convenient definitions or misleading compromises? 0ikos, 59: 417-421.

Farji-Brener, A.G. 2003. Microhabitat selection by antlion larvae, Myrmeleon crudenlis: effect of soil particle size on pit-trap design and capture. Journal of Insect Behavior, 16: 783-796.
Fisher, R.C. 1971. Aspects of the physiology of endoparasitic Hymenoptera. Biological Reviews, 46: 243-278.

Godfray, H.C.J. 1994. Parasitoids: Behavioral and Evolutionary Ecology. Princeton, Princeton University Press.

Jurberg, J. 1963. Contribuição para o estudo da morfologia de Myrmeleon januarius (Navas, 1916) (Neuroptera, Myrmeleontidae). Memórias do Instituto Oswaldo Cruz, 61: 165-176.

Leech, R. \& MacDonald-Leech, B.J. 1989. Dipalta serpentina Osten Sacken (Diptera: Bombyliidae) as a predator on pupae of the antlion Myrmeleon immaculatus Degeer (Neuroptera, Myrmeleontidae) in California. The Canadian Entomologist, 121: 727-728.

Levente, A. 1998. Micomitra stupida (Dpitera, Bombyliidae): a new parasite of Neuroleon nostras (Neuroptera, Myrmeleontidae). Dunántúli Dolgozatok Természettudományi Sorozat, 9: 421-422.

Lima, T.N. \& Faria, R.R. 2007. Seleção de Microhabitat por Larvas de Formigaleão Myrmeleon brasiliensis (Návas) (Neuroptera, Myrmeleontidae), em uma Reserva Florestal, Aquidauana, Mato Grosso do Sul. Neotropical Entomology, 35: 812-814.

Mackauer, M.; Michaud, M.R. \& Völkl, W. 1996. Host choice by aphidiid parasitoids (Hymenoptera, Aphidiidae): Host recognition, host quality, and value. The Canadian Entomologist, 120: 959-980.

Matsura, T.; Ohno, H. \& Sakamoto, M. 1998. Rate of parasitism of the antlion larvae, Myrmeleon bore (Neuroptera: Myrmeleontidae) by the bee fly, Villa myrmeleonostena (Diptera: Bombyliidae). Journal of Entomological Science, 1:321-325.

Missirian, G.L.B.; Uchôa-Fernandes, M.A. \& Fischer, E. 2006. Development of Myrmeleon brasiliensis (Navás) (Neuroptera, Myrmeleontidae), in laboratory, with different natural diets. Revista Brasileira de Zoologia, 23: 1044-1050.

New, T.R. 1991. Neuroptera. In: New, T.S. The Insects of Australia: a textbook for students and research workers. Melbourne, Melbourne University Press. v. 1, 525-542p.

Nicol, C.M.Y. \& Mackauer, M. 1999. The scaling of body size and mass in a hostparasitoid association: Influence of host species and stage. Entomologia Experimentalis et Applicata, 90: 83-92.

Nonato, L.M. \& Lima, T.N. 2011. Predation behavior of the Myrmeleon brasiliensis (Neuroptera: Myrmeleontidae) larval instars. Revista Colombiana de Entomologia, 37: 354-356.

$R$ Core Team. 2013. R: A language and environment for statistical computing. $R$ Foundation for Statistical Computing (online). Available at: www.rproject.org. Access in: 02/08/2012.

Sequeira, R. \& Mackauer, M. 1992. Nutritional Ecology of an Insect Host-Parasitoid Association: The Pea Aphid-Aphidius Ervi System. Ecology, 73: 183-189.

Simon, D. 1985. Observations on Nophis teillardi Navas (Neuroptera, Myrmeleontidae), with description of the larva. Israel Journal of Entomology, 19: 171-179.

Slansky, F. 1986. Nutritional ecology of endoparasitic insects and their hosts: An overview. Journal of Insect Physiology, 32: 255-261.

Steffan, J.R. 1961. Comportement de Lasiochalcidia igiliensis Ms., Chalcidide parasite de fourmilions. Compte Rendu Hebdomadaire des Séances de I'Académie des Sciences, 253: 2401-2403.

Uchôa, M.A. \& Missirian, G.L.B. 2014. Myrmeleon brasiliensis's Parasitoids (Neuroptera: Myrmeleontidae) in the South Pantanal, Brazil. Florida Entomologist, 97: 313-316.

Vinson, S.B. \& Iwantsch, G.F. 1980. Host regulation by insect parasitoids. The Quarterly Review of Biology, 55: 143-165.

Wheeler, W.M. 1930. Demons of the dust: a study in insect behaviour. New York, Norton. 